This item was submitted to Loughborough's Research Repository by the author.

Items in Figshare are protected by copyright, with all rights reserved, unless otherwise indicated.

\title{
A systematic review and meta-analysis of implicit theory research in sport, physical activity, and physical education
}

PLEASE CITE THE PUBLISHED VERSION

http://dx.doi.org/10.1080/1750984X.2016.1160418

\section{PUBLISHER}

(c) Taylor \& Francis

\section{VERSION}

AM (Accepted Manuscript)

\section{PUBLISHER STATEMENT}

This work is made available according to the conditions of the Creative Commons Attribution-NonCommercialNoDerivatives 4.0 International (CC BY-NC-ND 4.0) licence. Full details of this licence are available at: https://creativecommons.org/licenses/by-nc-nd/4.0/

\section{LICENCE}

CC BY-NC-ND 4.0

\section{REPOSITORY RECORD}

Vella, S.A., R.E. Braithwaite, L. Gardner, and Christopher Spray. 2016. "A Systematic Review and Metaanalysis of Implicit Theory Research in Sport, Physical Activity, and Physical Education”. Loughborough University. https://hdl.handle.net/2134/20691. 


\begin{abstract}
The purpose of this systematic review and meta-analysis was to gather, catalogue, assess and evaluate the available evidence examining implicit beliefs about ability in the sport, physical activity, and physical education contexts. A total of 43 studies were found, of which 39 were subjected to meta analyses. With only 7 experimental studies, the strength of evidence is moderate and the field would benefit from greater experimental work. Overall, incremental beliefs were moderately associated with a small group of theoretically-derived correlates, while entity beliefs were only weakly associated. The field would benefit from expanding these outcomes to include a wider range of pertinent outcomes. Researchers should focus their efforts on systematically exploring the most powerful ways of inducing adaptive implicit beliefs with the aim of providing solutions to significant problems such as preventing dropout from organised sports, improving academic grades in and beyond physical education, and increasing levels of physical activity.
\end{abstract}

Key words: implicit beliefs, self-theories, motivation, incremental beliefs, entity beliefs 


\section{A Systematic Review and Meta-Analysis of Implicit Theory Research in Sport, Physical}

\section{Activity, and Physical Education}

Implicit beliefs about human traits and abilities over a wide variety of domains have consistently been shown to influence one’s cognitions, affect, and behaviours (Burnette, O'Boyle, VanEpps, Pollack, \& Finkel, 2013; Dweck, 1999; W. Li \& Lee, 2004). Implicit beliefs are unconscious conceptions about the nature of human abilities and they exert a strong influence on motivational frameworks because they provide a schemata through which all achievement-related events are interpreted and responded to (Dweck \& Leggett, 1988). There are two basic implicit beliefs: incremental beliefs and entity beliefs. Those who hold an incremental belief regard ability as a malleable and incremental quality that can be trained and developed, while those who hold an entity belief regard ability as a fixed or concrete entity (Dweck, 1999).

Research across domains including sports, education, personality, and morality supports the adaptive benefits of incremental beliefs. Such benefits include higher rates of motivation, persistence and effort, a greater preference for learning and challenge, an ability to self-regulate behaviour, and an ability to generate strategies for improvement (Blackwell, Trzesniewski, \& Dweck, 2007; Burnette et al., 2013; Chiu, Dweck, Tong, \& Fu, 1997; Chiu, Hong, \& Dweck, 1997; Dweck \& Leggett, 1988; Gunderson et al., 2013; W. Li \& Lee, 2004). Furthermore, implicit beliefs are particularly powerful predictors of adaptive or maladaptive responses following a failure or setback (Dweck \& Leggett, 1988). As such, implicit beliefs may be important in sports and physical activity contexts where: failures and setback are numerous and occur often; the development of expertise requires effort and persistence over the course of many years; and the core goals of participation often relate to the development of human abilities. Both intervention and longitudinal studies in the school setting have provided a powerful demonstration of the benefits of adaptive implicit beliefs, 
particularly during the transition to adolescence, including greater health, reduced ill-health, and greater academic achievement (Blackwell et al., 2007; Yeager et al., 2014). As such, the application of the underlying theory to intervention and translational research seems to hold promise in bringing meaningful benefits.

Research on implicit beliefs in physical settings has evolved over more than twenty years, in highly varied contexts, using a range of outcome variables, and under the guise of several different terms including implicit theory, self-theory, ability beliefs, conceptions of ability, and mindset (e.g., Chase, 2010; Gao, Kosma, \& Harrison, 2009; Jourden, Bandura, \& Banfield, 1991; Kasimatis, Miller, \& Marcussen, 1996; Spray, Wang, Biddle, Chatzisarantis, \& Warburton, 2006). The disparate nature of the research has perhaps meant that its influence is not as great as it may have been. Given the ad hoc nature of over twenty years of research, and the fact that no other systematic and meta-analytic review of implicit beliefs research in sport, PE and physical activity has been undertaken, it was considered timely and necessary to gather, catalogue, assess and evaluate the available evidence and to present an informative summary. In so doing, we aimed to synthesise and bring some clarity to this area and to stimulate higher quality research so that meaningful benefits can be achieved within the sport, physical education, and physical activity contexts. The secondary purpose of this review was to compare and contrast the evidence by context, gender, age, culture, study design, measurement frequency, and reporting method. For example, it is possible that beliefs about ability have a stronger influence in a sports context where ability-based tasks are frequent and judgements regarding success are more overt than in physical activity contexts (Dweck, 1999). Furthermore, ability beliefs may also be stronger among older children who are more readily able to distinguish between ability and effort than younger children (Fry \& Duda, 1997) and may also differ by gender (Spray et al., 2006). Lastly, further purposes of the review were to identify gaps in the body of evidence, and provide specific directions for 
future research. As such, three key research questions were addressed: (1) What are the outcomes associated with implicit beliefs in sport, physical activity, and physical education contexts?; (2) What is the strength and quality of this evidence?; (3) Does the evidence differ by pertinent variables such as context, gender, age, culture, study design, measurement frequency, and reporting method?

\section{Methods}

Reporting of this systematic review has followed the Preferred Reporting Items for Systematic Reviews and Meta-Analyses (PRISMA) statement (Moher, Liberati, Tetzlaff, Altman, \& The PRISMA Group, 2009)

\section{Evidence Included in the Systematic Review}

Any study published or accepted for publication in a peer-reviewed journal that used a valid and reliable quantitative measure of implicit theory was eligible for inclusion in the systematic review. Each study was required to have been conducted in the context of sports, physical activity or physical education. No limits were set in regards to study design or sample size. There was no comparison group required, and no limits were placed on the outcomes of the study apart from the requirement of a measure of implicit beliefs. Similarly, no exclusion criteria were set in regards to participant characteristics. Conference abstracts, dissertations, theses, and articles published in non-peer reviewed journals were not included in the review to avoid potential duplication of data in the review and to impose a proxy measure of minimum scientific rigor for included studies. No date limits were set, and only studies that were reported in the English language were considered for inclusion.

\section{Database Search Strategy}

The terms used in literature search were negotiated between the authors. In particular, the search terms encompassed the range of terms under which research on implicit beliefs has been conducted. The search terms were deliberately selected to capture a wide range of 
potential evidence in order to ensure that no relevant evidence was missed. The full search strategy is presented in Table 1. An identical search strategy was conducted over five academic databases during the first two weeks September, 2014, including: MEDLINE; SportsDISCUS; PsycINFO; PubMed; and Scopus. Each search was conducted by a single researcher. Where possible, results were limited to: English language; abstract available online; peer reviewed; journal articles, and; human subjects. The results of each search were saved, and entered into an Endnote X3 database (Thompson Reuters, California). Duplicates were removed by the Endnote program, and where possible, duplicates were also removed manually prior to initial screening.

\section{Grey Literature Search Strategy}

Firstly, additional articles known to the authors and other content experts were assessed for possible inclusion. Content experts were identified following the database search, and were contacted by email. Secondly, the reference lists of retrieved full-text articles were searched, in addition to the reference lists of relevant review articles and excluded documents such as dissertations.

\section{Inclusion of Articles}

Initial screening of all articles collected in the database and grey literature searches was conducted by two independent researchers. The researchers screened each article by title and abstract for potential relevancy. Articles were retained for full-text screening if one reviewer deemed the article as potentially relevant. Full text copies of all retained articles were obtained, and screened for relevancy. Where articles were excluded at this stage, a reason for exclusion was documented. Secondary screening of full text articles was conducted by a single researcher. Where there was some ambiguity about the relevancy of any given article, this was discussed between two researchers and a consensus decision was reached. 


\section{Data Extraction}

Data were extracted from each of the included articles by one reviewer, with 10 (23\%) randomly chosen articles checked for accuracy by a second reviewer. There were no errors of data extraction evident in any of the randomly checked articles and data were extracted into an electronic database, including: author; date of publication; country of origin; study design; participant details; context of study (sport, physical activity or physical education); measure of implicit theory used; other relevant outcomes/correlates; measures of other relevant outcomes/correlates used; length of follow up (if any); control group used (if any); statistical analyses used; statistical measures of the relationship between implicit theory and other outcomes/correlates; covariates (if any), and; comments on overall quality of the study. Studies were grouped according to this information for the purposes of meta-analyses, including by outcome/correlates, participant gender and age, and study context.

\section{Assigning Risk of Bias and the Strength of Evidence}

The strength of the overall body of evidence was assessed using the Levels of Evidence adapted from Lau et al. (2007). The objective appraisal of the level of evidence is based upon a pre-specified scale that is determined by the study designs and quality. Within this framework randomised controlled trials are considered to have the highest level of evidence (Level 1) while anecdotal reports or inadequate data are considered to have the lowest evidence (Level 4). Where there were limitations evident in randomised controlled trials, the level of evidence that was assigned could drop from Level 1 to Level 2. An overwhelming level of evidence derived from cross-sectional studies is assigned as Level 2 evidence, while a small number of cross-sectional studies are considered as Level 3 evidence.

\section{Statistical Analyses}

Outliers and publication bias are problematic when conducting a statistical synthesis and to address these issues data were screened to determine if results were influenced. 
Outliers are large residual values (z-scores) two standard deviations $( \pm 1.96)$ above or below the study’s mean effect size. Decisions made to retain or exclude outliers were based on whether overall results remained significant $(\mathrm{p} \leq .05)$ and within the $95^{\text {th }}$ percent confidence interval. Publication bias or the 'file drawer problem' can influence meta-analytic results when relevant studies are missed or excluded when conducting the literature search process (Rosenthal, 1979; Rothstein, Sutton, \& Borenstein, 2005). Methods used to identify and control for publication bias included review of the funnel plot (Egger, Davey Smith, Schneider, \& Minder, 1997), a Fail Safe $N$ calculation (Rosenthal, 1979), and a 'Trim and Fill’ procedure (Duval \& Tweedie, 2000). Asymmetrical funnel (Borenstein, Hedges, Higgins, \& Rothstein, 2009; Light \& Pillemer, 1984) provide an initial estimate of the influence of publication bias requiring further analyses using both Fail-Safe $N$ and 'Trim \& Fill’ methods. Rosenthal's (1979) Fail Safe $N$ calculates the number of studies needed to nullify a significant effect and Duval and Tweedie’s (2000) 'Trim and Fill’ estimate yields an adjusted estimate of effect (if publication bias is present) through an iterative statistical procedure to calculate a symmetrical funnel plot.

Analyses were conducted with Comprehensive Meta-Analysis (CMA) version-2 software (Borenstein, Hedges, Higgins, \& Rothstein, 2005). Interpretation of the effect size calculations were based on Cohen's (1988) determination of small $(r \leq .10)$, medium $(r \leq$ .30), and large ( $r \geq .50)$ effect sizes. The study was considered to be the unit of analysis, therefore, when studies contained multiple measures (outcomes) CMA averages the different calculations into a summary effect. Pearson's $r\left(r_{-}\right)$was the effect size metric selected to determine the relationships between incremental and entity beliefs and other variables. Fisher's z score was used to compute the summary effect, variance, standard error, and confidence limits and was calculated using the following formula:

$$
z=0.5 x \ln \left(\frac{1+r}{1-r}\right)
$$


The formula used to compute Fisher's $z$ back to a correlation was:

$$
r=\frac{e^{2 z}-1}{e^{2 z}+1}
$$

To provide overview of the literature additional analyses (outcomes and moderator) were used to determine the magnitude of effect for specific relationships (outcome) as well as how effect sizes vary between moderating variables (sub-groups; i.e., study design, study context [physical activity, sport, physical education], gender, age, questionnaire frequency, and reporting method). Based on the purposes of the current investigation a random effects model was used to interpret findings and apply real world data (Field, 2001, 2003; Hunter \& Schmidt, 2000). A random effects model assumes error is connected to sampling procedures and additional between study variance (Borenstein, Hedges, Higgins, \& Rothstein, 2010; Hunter \& Schmidt, 2000). Analyses completed using a random effects model adjust effect sizes by the inverse weight of the variance to consider both the sampling and between study error (Borenstein et al., 2009).

Outcome Analyses

The outcomes reported across studies included a number of similar variables with different terminology. For example, mastery climate can also be referred to as task-involved climate. To be consistent in reporting the summary effect for different outcomes, the authors reviewed studies reporting measurement tools used to collect data and only reported outcome constructs that used similar measures across studies. To conduct outcome analyses studies were grouped by outcome measure. Further analyses were conducted on two groups whereby studies were sorted into their relationships with adaptive and maladaptive outcomes. Final groupings for outcome measures were agreed upon by all authors before analyses were completed.

\section{Subgroup Analyses}

Random effects models assume data (i.e., studies included) will be heterogeneous due 
to sampling and between study variance. Subgroup (moderator) analyses provide the strength and/or direction of relationships between independent and dependent variables (Shaddish \& Sweeney, 1991). In the current investigation we were interested in differences between number of levels of independent variables (e.g., age, gender, context, etc.) and various types of outcomes. Three statistics were used to evaluate heterogeneity and included the $Q$ Total $\left(Q_{T}\right)$, tau-squared $\left(\tau^{2}\right)$, and I-square $\left(I^{2}\right)$ values. The $Q_{T}$ value is based on a $\chi$-square $\left(\chi^{2}\right)$ distribution and is used to determine overall heterogeneity. When the $Q_{T}$ statistic is significant then variance is categorized into $Q_{\text {Between }}\left(Q_{B}\right)$ and $Q_{W i t h i n}\left(Q_{W}\right)$ values with significant $Q_{B}$ values $(\mathrm{p}<.05)$ requiring statistical techniques (i.e., $t$-test or ANOVA) to determine subgroup differences (Borenstein et al., 2009; Hedges \& Olkin, 1985). The tausquare $\left(\tau^{2}\right)$ value provides an estimate of total variance between studies and is also used to calculate study weights. The I-square $\left(I^{2}\right)$ value provides an estimate of the overlap of confidence intervals and is interpreted as low (25\%), moderate (50\%), or high (75\%) values of the total variance attributed to covariates (Higgins, Thompson, Deeks, \& Altman, 2003) Small subgroup sample sizes $(k \leq 5)$ may influence the precision of $\tau^{2}$; therefore, a pooled estimate of variance was used for all calculations (Borenstein et al., 2009).

\section{Results}

In total, 1,826 citations were entered into the Endnote database for initial screening. Researcher 1 retained 123 articles for full-text screening, while researcher 2 retained 91 articles. In total, there were 140 articles retained for review. Thus, 74 of the 140 articles were retained by both researchers. Low agreement at this stage reflects the conservative approach to initial screening and the wide variety in potential terms used to describe the construct under investigation. Secondary screening of full text articles resulted in a total of 43 articles containing 47 independent samples for inclusion in the final systematic review. A flow diagram of the study selection process appears in Figure 1. A full list of articles included in 
the review as well as the relevant coding information appears in Table 2. Only 39 studies were included in the final meta-analysis due to the necessary data being unobtainable from 4 studies. In total, data were collected from 18,336 participants with the majority of subjects between the ages of 11 to 23 (age range 11-62) representing 11 different countries.

\section{Qualitative Synthesis of the Evidence}

Of the 43 papers that were included in the systematic review, fourteen were undertaken within the sports context, thirteen within a physical activity or exercise context, and sixteen within a physical education context. Three papers reported on more than a single study (Biddle, Wang, Chatzisarantis, \& Spray, 2003; Sarrazin et al., 1996; Stevenson \& Lochbaum, 2008), 47 separate studies reported over the 43 papers. Thirty-seven of the 47 studies were cross-sectional in design, seven were experimental, and three were longitudinal. Participants were typically school (28 studies) or university students (13 studies). Major outcome variables were theoretically informed, including achievement goals (27 studies, 7 of which used the $2 \times 2$ model of achievement goals), perceived competence or self-efficacy (27 studies), motivation or amotivation (16 studies), and motivational climate (4 studies). The majority of included studies pertained to cognitive correlates of implicit beliefs, while very few pertained to behavioural correlates. In addition to those mentioned above, cognitive correlates included affect, enjoyment, and anxiety (e.g., Biddle et al., 2003; Kasimatis et al., 1996; Y. Ommundsen, 2001a). Behavioural correlates were most often a measure of physical activity or a measure of task performance. Other behavioural correlates included selfregulation, self-handicapping, reactions to success and failure, and effort (e.g., W. Li, Lee, \& Solmon, 2005; Y. Ommundsen, 2001b, 2003). Notable absences in outcome variables according to the underlying theory were behavioural measures such as persistence and engagement with challenging tasks. In sum, there is a high level of repetition (but not replication) within the body of literature, particularly using cross-sectional designs, with a 
notable failure to advance knowledge by including a variety of outcome measures, most notably behavioural measures.

Twelve of the studies used the bi-dimensional Conceptions of the Nature of Athletic Ability Questionnaire (CNAAQ; Sarrazin et al., 1996) which assesses entity and incremental beliefs in separate subscales. A further 25 used a revised version of the CNAAQ (CNAAQ-2; Biddle et al., 2003). Other measures used to capture implicit beliefs include the Implicit Self Theories Questionnaire - a five-item measure of beliefs about one’s 'health’ (Lochbaum, Bixby, Lutz, Parsons, \& Akerhielm, 2006), and a three-item scale reflecting a single bipolar construct from entity to incremental beliefs (Potgieter \& Steyn, 2010; Sarrazin et al., 1996; Sevincer, Kluge, \& Oettingen, 2014). A more specific measure adapted to hockey skills was used by Solmon and colleagues (2003). All measures were self-reported.

Six of the seven experimental studies manipulated implicit beliefs, while one used the CNAAQ-2 as an outcome measure (Moreno, Lacárcel, \& Del Villar Álvarez, 2010). Beliefs were manipulated using written instructions (Jourden et al., 1991; Moreno, González-Cutre, Martín-Albo, \& Cervelló, 2010), verbal instructions (Kasimatis et al., 1996; Lirgg, Chase, George, \& Ferguson, 1996; Spray et al., 2006), and video instructions (Belcher, Lee, Solmon, \& Harrison Jr, 2003). Only two studies conducted some form of manipulation check to examine whether the entity and incremental beliefs had successfully been induced (Lirgg et al., 1996; Spray et al., 2006).

\section{Strength and Quality of the Evidence}

A total of seven experimental and forty cross-sectional/longitudinal studies were not deemed sufficient for categorisation as Level 1 evidence. Some of the major flaws of the experimental studies as a body of evidence include a small range of outcome measures, an absence of replication studies, an absence of manipulation checks to confirm that beliefs were successfully induced, an absence of long-term follow-up measures, and small sample sizes. 
However, we believe that the forty cross-sectional studies justify categorisation of Level 2 evidence because the outcomes that have been investigated include a consistent cross-section of important and theoretically informed variables. Major correlates of implicit beliefs such as goal orientation, self-efficacy, and motivation have been replicated numerous times and findings are consistent across studies. In order to provide a greater level of evidence more randomised controlled studies are required that address the limitations mentioned above.

\section{Quantitative Analyses}

Meta-Analysis

Four studies were not able to be included in the meta-analysis because the data that were reported were insufficient (Belcher et al., 2003; Jourden et al., 1991; W. Li, Harrison, \& Solmon, 2004; Solmon et al., 2003). The coding characteristics of all other studies included in the analysis are provided in Table 2. The influence of outliers on the relationship between implicit beliefs and various outcomes was checked using a 'one study removed' procedure in CMA. The sensitivity analyses for both entity and incremental beliefs identified the same two studies (Chen et al., 2008; Wang, Liu, Biddle, \& Spray, 2005) as having standard residual values larger than two standard deviations above or below the mean. However, outliers were retained because the effects for incremental and entity beliefs were unchanged (i.e., within the 95\% confidence interval) following removal (see Table 3).

Six experimental studies were included in the quantitative analyses that reported mean differences between groups instead of relationships between variables and no transformations were performed to conduct the analyses. As single-sample correlations were not reported, and due to the sample size $(k=6)$ these studies have not been included in the outcome or moderator analyses (Tables 2-7), and findings have been reported separately. The summary treatment effect for interventions was significant $(k=6, g=0.09,95 \% C I=0.02,0.17, Z=$ 2.47, $p=.019$ ) across all outcomes. Results suggest modest improvements in groups where 
incremental beliefs were induced and that findings were invariant across outcomes as indicated by insignificant heterogeneous statistics $\left(Q_{T}(5)=7.11, I^{2}=29.65, p=.213\right)$.

\section{INSERT TABLE 2 ABOUT HERE}

\section{Outcome Analyses}

Individual relationships between implicit beliefs and adaptive and maladaptive outcomes are provided in Table 3. Correlations between entity beliefs and adaptive outcomes were significant $\left(k=23, r_{-}=-.11,95^{\%} C I=-.14,-.08, p<.001\right)$. Weak to moderate negative correlations were significant between entity beliefs and the Relative Autonomy Index (RAI; $k$ $\left.=7, r_{-}=-.32, p<.001\right)$ and other measures of intrinsic motivation $(k=6, r=-.12, p=.039)$. Maladaptive outcomes were significantly and positively correlated with entity beliefs $(k=19$, $\left.r_{-}=.17,95 \% \mathrm{CI}=.12, .21, p<.001\right)$. There were significant weak and moderate positive relationships between entity beliefs and ego orientation $\left(r_{-}=.13, p<.001\right)$, performance climate $\left(r_{-}=.34, p<.001\right)$, performance approach goals $\left(r_{-}=.18, p<.001\right)$, and performance avoidance goals $\left(r_{-}=.19, p<.001\right)$. Study variability for entity beliefs and both adaptive and maladaptive processes as measured by between study variance $\left(\tau^{2}\right)$ and overlap of confidence intervals $\left(I^{2}\right)$ statistics indicated consistent findings for mastery climate, RAI, mastery approach goals, ego, orientation, and performance climate. All other variables had inconsistent (high variability) markers indicating the need for moderator analyses for each outcome.

There was a significant $\left(k=28, r_{-}=.37,95 \% C I=.27,0.47, p<.001\right)$ positive relationship between incremental perceptions and adaptive processes with effect sizes ranging from small to moderate. Significant $(p<.05)$ positive relationships were found between incremental beliefs and the adaptive outcomes of task orientation $\left(r_{-}=.39, p<.001\right)$, mastery climates $\left(r_{-}=.40, p<.001\right)$, enjoyment $\left(r_{-}=.41, p<.001\right)$, perceived competence $\left(r_{-}=.27, p<.001\right)$, RAI $\left(r_{-}=.37, p<.001\right)$, intrinsic motivation $\left(r_{-}=.40, p<.001\right)$, and 
mastery approach goals $\left(r_{-}=.41, p<.001\right)$. Relationships between incremental beliefs and maladaptive outcomes did reveal a significant $(p=.037)$ overall effect size. Weak significant relationships were found between incremental beliefs and performance climate $\left(r_{-}=-.12, p<\right.$ $.001)$ and mastery avoidance goals $\left(r_{-}=.17, p<.001\right)$. Heterogeneity statistics indicated that there was a large degree of study variability. The between study variance $\left(\tau^{2}\right)$ and overlap of confidence intervals $\left(I^{2}\right)$ statistics indicated a need for moderator analyses for each outcome. Moderator analyses for specific outcomes were not conducted for the different moderators as there were insufficient data.

\section{INSERT TABLE 3 ABOUT HERE}

\section{Publication Bias}

Publication bias in the relationships between both incremental and entity beliefs and adaptive/maladaptive outcomes was unlikely as the Fail Safe $N$ calculations indicated that a large number of studies were needed to nullify the significant effects. All Fail Safe N's are given in Table 3. The trim and fill procedure adjusted the summary effect size for the overall relationships between entity beliefs and adaptive outcomes with a slight increase in correlation $(r=-.10,95 \%$ CI $=-.13,-.07, p<.05)$. A decreased correlation $(r=.02,95 \%$ CI $=$ $-.03, .06, p>.05$ ) was also observed between incremental perceptions and maladaptive outcomes. Results from the trim and fill procedures are indicative of unbalanced funnel plots, however, changes in the effect size calculations did not make substantial changes to effect sizes or corresponding confidence intervals.

\section{Moderator Analyses}

Borenstein and colleagues (2009) suggest that when subgroups are small $(\mathrm{k}<5)$ the estimate of effect size will be imprecise. We have selected to report these smaller subgroups to provide a summary of the literature and then where possible $(k>3)$ provide a conservative interpretation. All results are presented in Tables 4 and 5 (incremental beliefs) and Tables 6 
and 7 (entity beliefs). No variables were found to moderate the relationship between incremental beliefs and maladaptive outcomes (Table 5). In contrast, study design and participant gender moderated the relationship between incremental beliefs and adaptive outcomes (Table 4). In particular, longitudinal studies $\left(r_{-}=.45\right)$ yielded significantly greater $\left(Q_{B}(27)=5.08, p<.05\right)$ positive correlations between incremental beliefs and adaptive outcomes than cross-sectional studies $\left(r_{-}=.32\right)$. Female only $\left(r_{-}=.42\right)$ samples had significantly stronger positive relationships between incremental beliefs and adaptive outcomes than did combined $\left(r_{-}=.34\right)$ and male only $\left(r_{-}=.29\right)$ samples. Despite some trends being apparent, no other moderator variables were able to explain effect size differences (large $\tau^{2}$ and $I^{2}$ values). There were no significant differences in the relationships between entity beliefs and either adaptive (Table 6) or maladaptive (Table 7) outcomes by moderating variables. Sample sizes (smaller $\mathrm{k}<5$ ), effect sizes (below Cohen’s criteria $\mathrm{r}<$ .10), and heterogeneity statistics (larger degrees of variability) prevented drawing definitive conclusions from the data.

\section{INSERT TABLES 4-7 ABOUT HERE}

\section{Discussion}

This systematic review and meta-analysis aimed to synthesise research pertaining to implicit beliefs about ability within the sport, physical education, and physical activity contexts. Specifically, three key research questions were addressed: (1) What are the outcomes associated with implicit beliefs in sport, physical activity, and physical education contexts?; (2) What is the strength and quality of this evidence?; (3) Does the evidence differ by pertinent variables such as context, age, gender, culture, or reporting method? These three questions will be discussed in turn.

\section{Outcomes Associated with Implicit Beliefs}


Meta-analyses of outcome variables demonstrate significant associations between incremental and entity beliefs and a small range of theoretically-informed outcome variables. The most commonly studied correlates of implicit beliefs are goal orientations and motivational climate. Incremental beliefs are positively associated with a task orientation, mastery climate, mastery-approach goals, and mastery-avoidance. Incremental beliefs are negatively associated with a performance climate. In contrast, entity beliefs are positively associated with an ego orientation, performance climate, performance-approach goals, and performance-avoidance goals. Entity beliefs are negatively associated with a mastery climate. These results are consistent with the foundational theoretical and empirical work of Dweck and colleagues (Diener \& Dweck, 1978, 1980; Dweck, 1986; Dweck \& Leggett, 1988), whereby implicit beliefs about ability are hypothesised to influence behaviour because they give rise to the goals that one pursues within achievement contexts such as sport and PE to create a meaning system for individuals. Results are also consistent with an updated version of the original model revised to include the distinction between approach and avoidance goals (Elliot, 1999). Furthermore, findings are consistent with a meta-analysis of implicit beliefs research undertaken across a broad range of outcomes which suggests that the relationship between implicit beliefs and goal attainment is mediated by goal orientation, including approach and avoidance goals (Burnette, O'Boyle, VanEpps, Pollack, \& Finkel, 2013). Given this consistency, we suggest that additional cross-sectional studies investigating the relationships between implicit beliefs and goal orientations would not extend knowledge in this area. A small number of experimental studies may be warranted to provide empirical evidence on the directionality of the relationship between implicit beliefs and achievement goals.

Incremental beliefs are moderately associated with measures of intrinsic and autonomous motivation. Entity beliefs are weakly negatively associated with measures of 
intrinsic motivation and moderately negatively associated with measures of autonomous motivation. Thus, it seems that incremental beliefs allow individuals to pursue self-referent goals which are more likely to be self-determined in nature. In contrast, entity beliefs are likely to predispose individuals to pursue other-referent or performance goals which may be less likely to be self-determined and more likely to be extrinsic in nature. Limited research into the reasons for pursuing performance goals has been conducted in sport, physical activity, and physical education settings. We suggest that implicit beliefs represent a potentially insightful line of inquiry into understanding self-determined versus controlling forms of performance goal adoption. It is also possible that incremental beliefs predispose individuals to higher levels of perceived competence and greater levels of perceived autonomy by virtue of the belief that one's basic abilities can be changed and therefore the environment can be controlled. Pannekoek, Piek and Hagger (2013) have hypothesised a motivational sequence in children's physical activity contexts whereby implicit beliefs about ability give rise to achievement goals, which in turn influence the satisfaction of one's basic psychological needs of autonomy, competence, and relatedness. The satisfaction of basic psychological needs subsequently predicts the degree of self-determined motivation for physical activity. This presents an interesting platform for theoretical integration, which has been sparse when it comes to implicit belief research. It may be beneficial for researchers to include measures of achievement goals, basic psychological need satisfaction, and selfdetermined motivation in order to provide a fuller picture of the motivational processes and sequences which may underpin the benefits associated with adaptive implicit beliefs. Similarly, the role of entity beliefs in underpinning experiences of need thwarting and more controlling forms of motivation deserves attention.

Perceived competence is weakly associated with incremental beliefs but is not associated with entity beliefs. This is also likely due to those who hold incremental beliefs 
being likely to pursue self-referent goals (Dweck \& Leggett, 1988). As such, the conditions and criteria of success are placed in the hands of the individual and are decidedly more controllable than goals that are other-referent. As noted by Lepper, Master, and Quin Yow (2008), the motivational power of feelings of competence can be fragile, especially when the difficulty of the task is high. Those high in incremental beliefs are likely to exert greater effort following the experience of failure, while those high in entity beliefs are more likely to withdraw and give up following failure and thereby succumbing to feelings of incompetence. Nonetheless, it remains unclear exactly where perceived competence should fit within the overall social cognitive model of achievement motivation. In line with the explanation offered by Lepper et al. (2008), Dweck and Leggett (1988) offer perceived competence as a moderating variable between goal orientation and motivational outcomes. In contrast, in a revised model, perceived competence is hypothesised as an independent antecedent of goals (Elliot, 1999). The latter perspective infers that perceived competence and implicit beliefs may interact to influence outcomes directly, as well as via their effect on achievement goal adoption. Further research in the physical domain is needed to explore the relationships between perceived competence and implicit beliefs within contemporary models of achievement motivation.

Incremental beliefs are moderately associated with all outcomes except for ego orientation and performance approach and avoidance goals. In contrast, entity beliefs are not associated with enjoyment or perceived competence, and relationships between entity beliefs and outcomes are generally weak or very weak. It is unclear why the extent to which one believes that ability can be acquired is a better predictor of outcomes than the opposing belief that ability is a fixed entity. However, it is possible that incremental beliefs provide greater psychological value as they facilitate the adoption of self-referent goals and do not subject individuals to the negative psychological effects of perceived failure that are typically 
associated with high levels of entity beliefs in potentially highly valued and publicly visible domains (Dweck, 1999).

\section{Strength and Quality of the Evidence}

We deemed that the body of evidence was insufficient for categorisation at Level 1 based on a lack of controlled experimental evidence (Lau et al., 2007). In addition, the few experimental studies that were conducted examined only a small range of outcomes variables, lacked replication, and were generally of a low quality. In order to build the evidence base,

more well-designed randomised controlled experiments are needed, with a particular focus on both expanding the range of outcome variables and replication studies. Of particular note was a lack of manipulation checks that are needed to ascertain whether or not the manipulation of implicit beliefs was successfully conducted. Also noteworthy were small sample sizes and a lack of follow-up measures to ascertain the degree to which changes were maintained. The body of cross-sectional studies provides a sufficient validation of theoretical principles and evidence-based platform from which to move to a more solution-focussed approach to research. A solution-focussed approach is characterised by an emphasis on experimental research and represents a conscious attempt to move forward from correlational and theoretical work (Robinson \& Sirard, 2005) A solution-focussed approach can be applied to promote enjoyment and prevent dropout in organised sports, promote greater academic achievement in and beyond physical education, and promote greater intensity and duration of physical activity.

\section{Moderating Variables}

Meta-analyses showed a distinct lack of moderating factors, and this is perhaps indicative of a disparate body of literature that is seemingly characterised by a lack of a systematic research program and typical use of small sample sizes. For example, it may have been expected that the relationship between implicit beliefs and outcome variables would be 
strongest during early adolescence where transitions to high school can magnify the protective and adaptive benefits of incremental beliefs (Blackwell et al., 2007; Yeager et al., 2014). The lack of systematically conducted research perhaps obscures any potential moderating variables such as age. Moving forward, programs of research which are able to systematically address issues such as potential moderating variables are needed. In addition, the field would benefit from larger sample sizes as well as diversification of the populations under investigation. High school students and university students are over-represented and there is a need to extend findings to adults and elite athletes.

\section{Issues Relevant to Future Research}

To date, there has been only a narrow range of outcomes associated with implicit beliefs about ability. Most of these outcomes have a strong theoretical basis for their inclusion in correlational studies, and this has served to strengthen the theoretical framework that underpins the research line and leads to a degree of confidence in the core constructs that are at play in influencing adaptive outcomes. Nonetheless, there is now scope to diversify the correlates under investigation as well as the different pathways through which beliefs could be hypothesised to influence adaptive outcomes. In particular, behavioural outcomes such as effort, persistence, willingness to seek out challenge, and intensity of physical activity are notable omissions from the research and warrant inclusion as theoretically informed outcome variables (Dweck, 1999). Other notable omissions also include social and environmental antecedents of implicit beliefs. Knowledge of how entity and incremental beliefs are influenced can give rise to evidence-based interventions to promote adaptive outcomes in sport, PE, and physical activity such as motivation, enjoyment, continued participation, and health.

Meta-analyses showed distinct differences in the range and strength of correlates between incremental and entity beliefs and this may have implications for the measurement 
of implicit beliefs about ability. Such differences suggest that incremental and entity beliefs may be independent beliefs with independent effects. However, it is unclear whether this is a product of the measurement tool commonly used by researchers (CNAAQ and CNAAQ-2) which includes separate subscales for incremental and entity beliefs. This approach to measurement is inconsistent with other areas of implicit belief research including personality (Yeager et al., 2014), intelligence, emotional functioning (Romero, Master, Paunesku, Dweck, \& Gross, 2014), and cognitive resources (Job, Dweck, \& Walton, 2010), all of which operationalise incremental and entity beliefs as opposite ends of a single, dichotomous construct. In these domains implicit beliefs have been assessed with a short continuous scale containing both fixed and growth items in which high or low scores indicate a dominant belief. Scores are subsequently used to classify participants as 'entity or incremental theorists', reflecting their dominant belief. The beliefs are viewed as dichotomous, although measured using one continuous scale.

Despite the inconsistency in approaches to measurement of implicit beliefs, there may be some benefits to a more comprehensive approach whereby entity and incremental beliefs are measured independently. For example, correlations between entity and incremental beliefs are typically weak-to-moderate and negative, suggesting they do not represent opposite ends of a single, bipolar construct (Biddle et al., 1999; Lintunenet et al., 1999; Ommundsen, 2003; Sarrazin et al., 1996; Wang \& Biddle, 2003). As such, measuring entity and incremental beliefs separately enables the examination of within-person belief profiles. An individual can believe quite strongly that certain elements of sport ability are fixed whereas other contributory qualities (referents) are malleable - a ‘high-high’ profile. Qualitative work with elite athletes has demonstrated the complexities inherent in the nuanced nature of entity and incremental beliefs. Typically, athletes conceptualise their sporting attainment as a consequence of many and diverse personal attributes, some of which 
they view as fixed, and others of which they consider much more malleable through effort and practice (Jowett \& Spray, 2013; Slater et al., 2012). As such, while evidence exists to suggest that the distinction between entity and incremental beliefs may be a meaningful one, it may be important to reconcile the way that implicit beliefs are operationalised with other prominent areas of study or to choose an approach to measurement that is conceptually and empirically consistent with the research questions under examination.

A dearth of experimental research $(k=6)$ means that researchers and practitioners are unclear on the most compelling and enduring methods of manipulating implicit beliefs. Furthermore, a lack of follow-up measures means that it is also unclear how long manipulations of beliefs are likely to last, while a lack of manipulation checks means that we cannot conclude with any certainty that the current methods have been effective. Spray et al. (2006) used a text passage which was read by participants to manipulate beliefs, and have shown that this was an effective means of manipulating implicit beliefs. However, higher impact and more meaningful methods may include visual, auditory, or interactive methods. It is also likely that the methods used to manipulate implicit beliefs will be highly contextualised and perhaps even individualised. Knowledge of the best methods to manipulate implicit beliefs is necessary to engage in effective solution-focussed, experimental research.

Lastly, it is worth considering that the way that one accesses, interprets, and acts upon one's implicit beliefs may differ by context. For example, in what situations may implicit beliefs about ability become hyper- or hypo-accessible? Are there subtle differences between beliefs about ability related to sport, PE, and physical activity that mean that implicit beliefs can operate differentially according to the context one is acting within (cf. Leith et al., 2014)? Furthermore, can social or environmental variables such a mastery-climate or coach behaviour override one's individual implicit beliefs to the extent where their influence 
becomes negligible? Finally, is there a form of universal implicit belief about an individual's ability to change that influences beliefs about one's sporting ability, and how amenable to change are specific beliefs about ability without addressing the potential universal belief?

\section{Limitations}

By only including published studies in this systematic review it is plausible that the conclusions reached suffer from publication bias. The inclusion of several contexts, namely sport, physical education, and physical activity, assumes that the implicit beliefs did not differ by context in order for the outcome analyses to be meaningful. Further, we are currently not aware of important moderating influences because of a lack of replication among studies, and this precludes examination of potential moderating variables. The almost universal reliance on the CNAAQ and CNAAQ-2 as a measure of implicit beliefs also precludes examination of implicit beliefs as a single and dichotomous construct, as is the norm among other areas of implicit beliefs research. As such, it is not possible to compare findings to other areas.

\section{Conclusion}

Incremental beliefs demonstrate a moderately strong relationship with a limited set of theoretically-informed correlates, and appear more strongly related to a wider variety of outcomes than entity beliefs. Given the current synthesis of evidence, athletes, coaches, and psychology practitioners should focus on facilitating high levels of incremental beliefs due to the demonstrated association with adaptive outcomes including mastery goals, intrinsic and autonomous motivation, enjoyment, and perceived competence. However, to inform and support strategies that may be used by athletes, coaches and practitioners, researchers need to adopt a solution-oriented approach, characterised by an emphasis on experimental research. We recommend researchers should focus their efforts on systematically exploring the most powerful ways of inducing adaptive implicit beliefs with the aim of providing solutions to 
significant problems such as preventing dropout from organised sports, improving academic grades in and beyond physical education, and increasing levels of physical activity. 


\section{References}

Belcher, D., Lee, A. M., Solmon, M. A., \& Harrison Jr, L. (2003). The influence of genderrelated beliefs and conceptions of ability on women learning the hockey wrist shot. Research Quarterly for Exercise \& Sport, 74, 183-192.

*Biddle, S. J. H., Seos, I., \& Chatzisarantis, N. (1999). Predicting physical activity intentions using a goal perspectives approach: a study of Hungarian youth. Scandinavian Journal of Medicine \& Science in Sports, 9, 353-357. doi: 10.1111/j.16000838.1999.tb00256.x

*Biddle, S. J. H., \& Wang, C. K. J. (2003). Motivation and self-perception profiles and links with physical activity in adolescent girls. Journal of Adolescence, 26, 687-701. doi: 10.1016/j.adolescence.2003.07.003

*Biddle, S. J. H., Wang, C. K. J., Chatzisarantis, N. L. D., \& Spray, C. M. (2003). Motivation for physical activity in young people: entity and incremental beliefs about athletic ability. Journal of sports sciences, 21, 973-989. doi: $10.1080 / 02640410310001641377$

Blackwell, L. S., Trzesniewski, K. H., \& Dweck, C. S. (2007). Implicit theories of intelligence predict achievement across adolescent transition: A longitudinal study and an intervention. Child Development, 78, 246-263. doi: 10.1111/j.14678624.2007.00995.x

Borenstein, M., Hedges, L., Higgins, J. P., \& Rothstein, H. R. (2005). Comprehensive MetaAnalysis Version 2. Engelwood, NJ: Biostat.

Borenstein, M., Hedges, L. V., Higgins, J. P. T., \& Rothstein, H. R. (2009). Introduction to meta-analysis. Chichester, UK: Wiley. 
Borenstein, M., Hedges, L. V., Higgins, J. P. T., \& Rothstein, H. R. (2010). A basic introduction to fixed effect and random effects models for meta-analysis. Research Synthesis Methods, 1, 97-111.

Burnette, J. L., O'Boyle, E. H., VanEpps, E. M., Pollack, J. M., \& Finkel, E. J. (2013). Mindsets matter: A meta-analytic review of implicit theories and self-regulation. Psychological Bulletin, 139, 655-701. doi: 10.1037/a0029531

Chase, M. A. (2010). Should coaches believe in innate ability? The importance of leadership mindset. Quest, 62, 296-307.

*Chen, L. H., Chen, M. Y., Lin, M. S., Kee, Y. H., Kuo, C. F., \& Shui, S. H. (2008). Implicit theory of athletic ability and self-handicapping in college students. Psychological Reports, 103, 476-484. doi: 10.2466/pr0.103.2.476-484

*Chian, L. K. Z., \& Wang, C. K. J. (2008). Motivational profiles of junior college athletes: A cluster analysis. Journal of Applied Sport Psychology, 20, 137-156. doi: $10.1080 / 10413200701805265$

Chiu, C., Dweck, C. S., Tong, J. Y., \& Fu, J. H. (1997). Implicit theories and conceptions of morality. Journal of Personality and Social Psychology, 73(5), 923-940. doi: 0022$3514 / 97 / 53.00$

Chiu, C., Hong, Y., \& Dweck, C. S. (1997). Lay dispositionism and implicit theories of personality. Journal of Personality and Social Psychology \& Health, 73, 19-30.

Cohen, J. (1988). Statistical Power Analysis for the Behavioral Sciences (2nd ed.). Hillsdale: Lawrence Earlbaum Associates.

*Corrion, K., D'Arripe-Longueville, F., Chalabaev, A., Schiano-Lomoriello, S., Roussel, P., \& Cury, F. (2010). Effect of implicit theories on judgement of cheating acceptability in physical education: the mediating role of achievement goals. Journal of Sports Sciences, 28, 909-919. 
*Cury, F., Da Fonséca, D., Rufo, M., \& Sarrazin, P. (2002). Perceptions of competence, implicit theory of ability, perception of motivational climate, and achievement goals: A test of the trichotomous conceptualization of endorsement of achievement motivation in the physical education setting. Perceptual and Motor Skills, 95, 233244.

Diener, C. I., \& Dweck, C. S. (1978). An analysis of learned helplessness: Continuous changes in performance, strategy, and achievement cognitions following failure. Journal of Personality and Social Psychology, 36, 451-462.

Diener, C. I., \& Dweck, C. S. (1980). An analysis of learned helplessness: II. The processing of success. Journal of Personality and Social Psychology, 39, 940-952.

Duval, S., \& Tweedie, R. (2000). Trim and fill: A simple funnel-plot-based method of testing and adjusting for publication bias in meta-analysis. Biometrics, 56, 455-463.

Dweck, C. S. (1986). Motivational processes affecting learning. American Psychologist, 41, 1040-1048.

Dweck, C. S. (1999). Self-theories: Their role in motivation, personality, and development. Philadelphia: Psychology Press.

Dweck, C. S., \& Leggett, E. L. (1988). A social-cognitive approach to motivation and personality. Psychological Review, 95, 256-273.

Egger, M., Davey Smith, G., Schneider, M., \& Minder, C. (1997). Bias in meta-analysis detected by a simple, graphical test. BMJ, 315, 629-634.

Elliot, A. J. (1999). Approach and avoidance motivation and achievement goals. Educational Psychologist, 34, 169-189.

*Emile, M., Chalabaev, A., Stephan, Y., Corrion, K., \& d'Arripe-Longueville, F. (2014). Aging stereotypes and active lifestyle: Personal correlates of stereotype 
internalization and relationships with level of physical activity among older adults. Psychology of Sport \& Exercise, 15, 198-204. doi: 10.1016/j.psychsport.2013.11.002

Field, A. P. (2001). Meta-analysis of correlation coefficients: A Monte Carlo comparison of fixed- and random-effects methods. Psychological Methods, 6, 161-180.

Field, A. P. (2003). Can meta-analysis be trusted? The Psychologist, 16, 642-645.

Fry, M. D., \& Duda, J. L. (1997). A developmental examination of children's understanding of effort and ability in the physical and academic domains. Research Quarterly in Exercise and Sport, 68, 331-344.

Gao, Z., Kosma, M., \& Harrison, L., Jr. (2009). Ability Beliefs, Task Value, and Performance as a Function of Race in a Dart-Throwing Task. Research Quarterly for Exercise and Sport, 80, 122-130.

Gunderson, E. A., Gripshover, S. J., Romero, C., Dweck, C. S., Goldin-Meadow, S., \& Levine, S. C. (2013). Parent praise to 1- to 3-year-olds predicts chidlren's motivational frameworks 5 years later. Child Development, 84, 1526-1541. doi: 10.1111/cdev.12064

Hedges, L. V., \& Olkin, I. (1985). Statistical methods for meta-analysis. Orlando, FL: Academic Press.

Higgins, J. P., Thompson, S. G., Deeks, J. J., \& Altman, D. G. (2003). Measuring inconsistency in meta-analyses. BMJ, 327, 557-560. doi: 10.1136/bmj.327.7414.557

Hunter, J. E., \& Schmidt, F. L. (2000). Fixed effects vs. random effects meta-analysis models: implications for cumulative knowledge in psychology. International Journal of Selection and Assessment, 8, 275-292.

Job, V., Dweck, C. S., \& Walton, G. M. (2010). Ego-depletion - Is it all in your head?: Implicit theories about willpower affect self-regulation. Psychological Science, 21, 1686-1693. doi: 10.1177/0956797610384745 
Jourden, F., Bandura, A., \& Banfield, J. T. (1991). The impact of conceptions of ability on self-regulatory factors and motor skill acquisition. Journal of Sport \& Exercise Psychology, 13, 213-226.

Jowett, N., \& Spray, C. M. (2013). British Olympic hopefuls: The antecedents and consequences of implicit ability beliefs in elite track and field athletes. Psychology of Sport and Exercise, 14, 145-153.

*Kasimatis, M., Miller, M., \& Marcussen, L. (1996). The effects of implicit theories on exercise motivation. Journal of Research in Personality, 30, 510-516.

Lau, D. C., Douketis, J. D., Morrison, K. M., Hramiak, I. M., Sharma, A. M., \& Ur, E. (2007). 2006 Canadian clinical practice guidelines on the management and prevention of obesity in adults and children. . Canadian Medical Association Journal, 176, S113.

Lepper, M. R., Master, A., \& Quin Yow, W. (2008). Intrinsic motivation in education. In S. Karabenick \& T. C. Urdan (Eds.), Advances in motivation and achievement (pp. 521555). Bingley, UK: Emerald Group Publishing.

Li, W., Harrison, L. J., \& Solmon, M. (2004). College students' implicit theories of ability in sports: Race and gender differences. Journal of Sport Behavior, 27, 291-304.

Li, W., \& Lee, A. (2004). A Review of Conceptions of Ability and Related Motivational Constructs in Achievement Motivation. Quest, 56, 439-461.

*Li, W., Lee, A. M., \& Solmon, M. (2005). Relationships among dispositional ability conceptions, intrinsic motivation, perceived competence, experience, persistance, and performance. Journal of Teaching in Physical Education, 24, 51-65.

*Li, W., Solmon, M. A., Lee, A. M., Purvis, G., \& Chu, H. (2007). Examining the relationships between students' implicit theories of ability, goal orientations and the preferred type of augmented feedback. Journal of Sport Behavior, 30, 280-291. 
Light, R. J., \& Pillemer, D. B. (1984). Summing up: The science of reviewing research. Cambridge, MA: Harvard University Press.

*Lintunen, T., Valkonen, A., Leskinen, E., \& Biddle, S. J. H. (1999). Predicting physical activity intentions using a goal perspectives approach: a study of Finnish youth. Scandinavian Journal of Medicine \& Science in Sports, 9, 344-352. doi: 10.1111/j.1600-0838.1999.tb00255.x

*Lirgg, C. D., Chase, M. A., George, T. R., \& Ferguson, R. H. (1996). Impact of conception of ability and sex-type of task on male and female self-efficacy. Journal of Sport \& Exercise Psychology, 18, 426-434.

*Lochbaum, M. R., Bixby, W. R., Lutz, R. S., Parsons, M., \& Akerhielm, T. (2006). Implicit theories and physical activity patterns: The mediating role of task orientation. Individual Differences Research, 4, 58-67.

*Lodewyk, K. (2009). Relations among beliefs about epistemology, ability conceptions, and achievement in high school physical education students. Physical Educator, 66, 124.

Moher, D., Liberati, A., Tetzlaff, J., Altman, D. G., \& The PRISMA Group. (2009). Preferred Reporting Items for Systematic Reviews and Meta-Analyses: The PRISMA Statement. PLoS Medicine, 6, e1000097. doi: 10.1371/journal.pmed.1000097

*Moreno, J. A., González-Cutre, D., Martín-Albo, J., \& Cervelló, E. (2010). Motivation and performance in physical education: An experimental test. Journal of Sports Science and Medicine, 9, 79-85.

*Moreno, J. A., González-Cutre, D., Sicilia, Á., \& Spray, C. M. (2010). Motivation in the exercise setting: Integrating constructs from the approach-avoidance achievement goal framework and self-determination theory. Psychology of Sport \& Exercise, 11, 542-550. doi: 10.1016/j.psychsport.2010.06.003 
*Moreno, J. A., Lacárcel, J. A. V., \& Del Villar Álvarez, F. (2010). Search for autonomy in motor task learning in physical education university students. European Journal of Psychology of Education, 25, 37-47. doi: 10.1007/s10212-009-0008-7

*Ommundsen, Y. (2001a). Pupils' affective responses in physical education classes: The association of implicit theories of the nature of ability and achievement goals. European Physical Education Review, 7, 219-242.

*Ommundsen, Y. (2001b). Self-handicapping strategies in physical education classes: The influence of implicit theories of the nature of ability and achievement goal orientations. Psychology of Sport and Exercise, 2, 139-156.

*Ommundsen, Y. (2001c). Students' implicit theories of ability in physical education classes: The influence of motivational aspects of the learning environment. Learning Environments Research, 4, 139-158. doi: 10.1023/a:1012495615828

*Ommundsen, Y. (2003). Implicit theories of ability and self-regulation strategies in physical education classes. Educational Psychology: An International Journal of Experimental Educational Psychology, 23, 141-157.

*Ommundsen, Y., Haugen, R., \& Lund, T. (2005). Academic self-concept, implicit theories of ability, and self-regulation strategies. Scandinavian Journal of Educational Research, 49, 461-474.

Pannekoek, L., Piek, J. P., \& Hagger, M. S. (2013). Motivation for physical activity in children: A moving matter in need for study. Human Movement Science, 32, 10971115.

*Potgieter, R. D., \& Steyn, B. J. M. (2010). Goal orientation, self-theories and reactions to success and failure in competitive sport. African Journal for Physical, Health Education, Recreation \& Dance, 16, 635-647. 
Robinson, T. N., \& Sirard, J. R. (2005). Preventing childhood obesity: A solution-oriented research paradigm. American Journal of Preventive Medicine, 28, 194-201. doi: 10.1016/j.ameepre.2004.10.030

Romero, C., Master, A., Paunesku, D., Dweck, C. S., \& Gross, J. J. (2014). Academic and emotional functioning in middle school: The role of implicit theories. Emotion, 14, 227-234. doi: 10.1037/a0035490

Rosenthal, R. (1979). The "File Drawer Problem" and tolerance for null results. Psychological Bulletin, 86, 638-641.

Rothstein, H. R., Sutton, A. J., \& Borenstein, M. (2005). Publication bias in meta-analysis: prevention assessment and adjustments. Chichester, UK: John Wiley.

*Sarrazin, P., Biddle, S. J. H., Famose, J.-P., Cury, F., Fox, K., \& Durand, M. (1996). Goal orientations and conceptions of the nature of sport ability in children: A social cognitive approach. British Journal of Social Psychology, 35, 399-414. doi: 10.1111/j.2044-8309.1996.tb01104.x

Sevincer, A. T., Kluge, L., \& Oettingen, G. (2014). Implicit theories and motivational focus: Desired future versus present reality. Motivation and Emotion, 38, 36-46. doi: 10.1007/s11031-013-9359-0

Shaddish, W. R., \& Sweeney, R. B. (1991). Mediators and moderators in meta-analysis: There's a reason we don't let dodo birds tell us which psychotherapies should have prizes. Journal of Consulting and Clinical Psychology, 59, 883-893.

Slater, M. J., Spray, C. M., \& Smith, B. M. (2012). "You're only as good as your weakest link": Implicit theories of golf ability. Psychology of Sport and Exercise, 13, 280-290. doi: 10.1016/j.psychsport.2011.11.010 
Solmon, M. A., Lee, A. M., Belcher, D., Harrison Jr, L., \& Wells, L. (2003). Beliefs about gender appropriateness, ability, and competence in physical activity. Journal of Teaching in Physical Education, 22, 261-279.

*Spray, C. M., Wang, C. K. J., Biddle, S. J. H., Chatzisarantis, N. L. D., \& Warburton, V. E. (2006). An experimental test of self-theories of ability in youth sport. Psychology of Sport \& Exercise, 7, 255-267. doi: 10.1016/j.psychsport.2005.05.001

*Stevenson, S. J., \& Lochbaum, M. R. (2008). Understanding exercise motivation: Examining the revised social-cognitive model of achievement motivation. Journal of Sport Behavior, 31, 389-412.

Vella, S. A., Cliff, D. P., Weintraub, D., Okely, A. D., \& Robinson, T. N. (2014). Instructional strategies to facilitate implicit beliefs in youth sport and physical activity. Quest, 66, 357-370.

*Wang, C. K. J., \& Biddle, S. J. H. (2001). Young people's motivational profiles in physical activity: A cluster analysis. Journal of Sport \& Exercise Psychology, 23, 1-22.

*Wang, C. K. J., \& Biddle, S. J. H. (2003). Intrinsic motivation towards sports in Singaporean students: The role of sport ability beliefs. Journal of health psychology, 8, 515-523. doi: 10.1177/13591053030085004

*Wang, C. K. J., Chatzisarantis, N. L. D., Spray, C. M., \& Biddle, S. J. H. (2002). Achievement goal profiles in school physical education: differences in selfdetermination, sport ability beliefs, and physical activity. The British journal of educational psychology, 72, 433-445.

*Wang, C. K. J., Chia, Y. H. M., Quek, J. J., \& Liu, W. C. (2006). Patterns of physical activity, sedentary behaviors, and psychological determinants of physical activity among Singaporean school children. International Journal of Sport and Exercise Psychology, 4, 227. doi: 10.1080/1612197x.2006.9671797 
*Wang, C. K. J., \& Koh, T. H. M. (2006). Sport ability beliefs, achievement goals, selfdetermination and beliefs about the purposes of physical education among Singaporean preservice physical education trainees. Asian Journal of Exercise \& Sports Science, 3, 25-34.

*Wang, C. K. J., \& Liu, W. C. (2007). Promoting enjoyment in girls' physical education: The impact of goals, beliefs, and self-determination. European Physical Education Review, 13, 145-164. doi: 10.1177/1356336x07076875

*Wang, C. K. J., Liu, W. C., \& Biddle, S. J. H. (2003). Female secondary students' sport ability beliefs and regulatory styles: Relationships with enjoyment, effort and boredom. Journal of Tianjin Institute of Physical Education, 18, 13-18.

*Wang, C. K. J., Liu, W. C., Biddle, S. J. H., \& Spray, C. M. (2005). Cross-cultural validation of the Conceptions of the Nature of Athletic Ability Questionnaire Version 2. Personality and Individual Differences, 38, 1245-1256.

*Wang, C. K. J., Liu, W. C., Lochbaum, M. R., \& Stevenson, S. J. (2009). Sport ability beliefs, 2 x 2 achievement goals, and intrinsic motivation: The moderating role of perceived competence in sport and exercise. Research Quarterly for Exercise and Sport, 80, 303-312.

*Warburton, V. E., \& Spray, C. M. (2008). Motivation in physical education across the primary-secondary school transition. European Physical Education Review, 14, 157178.

*Warburton, V. E., \& Spray, C. M. (2009). Antecedents of approach-avoidance achievement goal adoption in physical education: A longitudinal perspective. Journal of Teaching in Physical Education, 28, 214-232. 
*Warburton, V. E., \& Spray, C. M. (2013). Antecedents of approach-avoidance achievement goal adoption: An analysis of two physical education activities. European Physical Education Review, 19, 215-231. doi: 10.1177/1356336X13486055

Yeager, D. S., Johnson, R., Spitzer, B. J., Trzesniewski, K. H., Powers, J., \& Dweck, C. S. (2014). The far-reaching effects of believing people can change: Implicit theories of personality shape stress, health, and achievement during adolescence. Journal of Personality and Social Psychology, 106, 867-884. 
Figure 1. PRISMA Flow diagram of Literature search. 
Table 1. The search strategy

\begin{tabular}{ll}
\hline$\#$ & Search Terms \\
\hline 1 & $\begin{array}{l}\text { Implicit theor* OR self theor* OR ability belief* OR achievement motivation OR } \\
\text { conception* of ability }\end{array}$ \\
2 & $\begin{array}{l}\text { Sport OR physical education OR PE OR physical activity OR exercise } \\
3\end{array}$ \\
\hline
\end{tabular}


Table 2. Coding characteristics for studies included in the meta-analysis

\begin{tabular}{|c|c|c|c|c|c|c|c|c|}
\hline \multirow[b]{2}{*}{ Study } & \multicolumn{4}{|c|}{ Methodological Characteristics } & \multicolumn{4}{|c|}{ Sample Characteristics } \\
\hline & Design & Activity & Measure & Frequency & $\underline{\text { Age }}$ & Gender & Country & $\underline{\mathbf{N}}$ \\
\hline Biddle et al., 1999 & $\mathrm{D}$ & $\mathrm{S}$ & $\overline{\text { CNAAQ }}$ & 1 & $\mathrm{M}$ & $\mathrm{NR}$ & Hungary & 723 \\
\hline \multirow[t]{3}{*}{ Biddle et al., 2003a } & $\mathrm{D}$ & PA & CNAAQ & 1 & $\mathrm{H}$ & $\mathrm{B}$ & UK & 218 \\
\hline & $\mathrm{D}$ & PA & CNAAQ-2 & 1 & M & $\mathrm{B}$ & UK & 3019 \\
\hline & $\mathrm{D}$ & PA & CNAAQ-2 & 1 & $\mathrm{H}$ & $\mathrm{B}$ & UK & 570 \\
\hline Biddle et al., 2003b & $\mathrm{D}$ & PA & CNAAQ-2 & 1 & M & $\mathrm{F}$ & UK & 516 \\
\hline Chen et al., 2008 & $\mathrm{D}$ & $\mathrm{S}$ & CNAAQ-2 & 1 & 0 & $\mathrm{~B}$ & China & 264 \\
\hline Chian \& Wang, 2008 & $\mathrm{D}$ & $\mathrm{S}$ & CNAAQ-2 & 1 & $\mathrm{H}$ & B & Singapore & 306 \\
\hline Corrion et al., 2010 & $\mathrm{D}$ & $\mathrm{PE}$ & CNAAQ & 1 & M & $\mathrm{B}$ & France & 477 \\
\hline Cury et al., 2002 & $\mathrm{D}$ & PE & CNAAQ & 1 & M & M & France & 682 \\
\hline Emile et al., 2014 & $\mathrm{D}$ & PA & CNAAQ & 1 & 0 & B & France & 192 \\
\hline Kasimatis et al., 1996 & $\mathrm{E}$ & PA & Other & 2 & 0 & NR & US & 50 \\
\hline Li et al., 2005 & $\mathrm{E}$ & $\mathrm{PE}$ & CNAAQ-2 & 2 & 0 & $\mathrm{~F}$ & US & 98 \\
\hline LI et al., 2007 & $\mathrm{D}$ & $\mathrm{S}$ & CNAAQ & 1 & 0 & $\mathrm{~B}$ & US & 115 \\
\hline Lintunen et al., 1999 & $\mathrm{D}$ & PA & CNAAQ & 1 & M & B & UK & 401 \\
\hline Lirgg et al., 1996 & $\mathrm{E}$ & $\mathrm{S}$ & Other & 1 & 0 & $\mathrm{~B}$ & US & 160 \\
\hline Lochbaum et al., 2006 & $\mathrm{D}$ & PA & Other & 1 & 0 & $\mathrm{~B}$ & US & 515 \\
\hline Lodewyk et al., 2009 & $\mathrm{D}$ & $\mathrm{PE}$ & CNAAQ-2 & 1 & NR & M & Canada & 338 \\
\hline Moreno et al., 2010a & $\mathrm{E}$ & $\mathrm{PE}$ & Other & 1 & M & $\mathrm{B}$ & Spain & 363 \\
\hline Moreno et al., 2010b & $\mathrm{D}$ & PA & CNAAQ-2 & 1 & 0 & B & Spain & 727 \\
\hline Moreno et al., 2010c & $\mathrm{E}$ & PA & CNAAQ-2 & 2 & 0 & NR & Spain & 42 \\
\hline Ommundsen, 2001a & $\mathrm{D}$ & $\mathrm{PE}$ & CNAAQ & 1 & $\mathrm{H}$ & B & Norway & 343 \\
\hline Ommundsen et al., $2001 \mathrm{~b}$ & $\mathrm{D}$ & $\mathrm{PE}$ & CNAAQ & 1 & $\mathrm{H}$ & $\mathrm{B}$ & Norway & 217 \\
\hline Ommundsen et al., 2001c & $\mathrm{D}$ & $\mathrm{PE}$ & CNAAQ & 1 & $\mathrm{H}$ & $\mathrm{B}$ & Norway & 217 \\
\hline Ommundsen et al., 2003 & $\mathrm{D}$ & $\mathrm{PE}$ & CNAAQ & 1 & $\mathrm{H}$ & $\mathrm{B}$ & Norway & 343 \\
\hline Ommundsen et al., 2005 & $\mathrm{D}$ & $\mathrm{PE}$ & CNAAQ & 1 & 0 & $\mathrm{~B}$ & Norway & 228 \\
\hline Pogieter \& Steyn, 2010 & $\mathrm{D}$ & $\mathrm{S}$ & Other & 1 & 0 & NR & S. Africa & 80 \\
\hline \multirow[t]{2}{*}{ Sarrazin et al., 1996} & $\mathrm{D}$ & $\mathrm{S}$ & CNAAQ & 1 & M & $\mathrm{B}$ & France & 194 \\
\hline & $\mathrm{D}$ & $\mathrm{S}$ & CNAAQ & 1 & M & $\mathrm{B}$ & France & 304 \\
\hline Spray et al., 2006 & $\mathrm{E}$ & $\mathrm{S}$ & CNAAQ-2 & 1 & M & B & UK & 123 \\
\hline \multirow[t]{2}{*}{ Stevenson \& Lochbaum, 2008} & $\mathrm{D}$ & $\mathrm{PA}$ & CNAAQ-2 & 1 & 0 & B & US & 379 \\
\hline & $\mathrm{D}$ & PA & CNAAQ-2 & 1 & 0 & B & US & 148 \\
\hline Wang \& Biddle, 2001 & $\mathrm{D}$ & PA & CNAAQ-2 & 1 & M & $\mathrm{B}$ & UK & 2150 \\
\hline Wang et al., 2002 & $\mathrm{D}$ & PA & CNAAQ-2 & 1 & M & M & UK & 427 \\
\hline Wang \& Biddle, 2003a & $\mathrm{D}$ & PA & CNAAQ-2 & 1 & 0 & 0 & Singapore & 155 \\
\hline
\end{tabular}




\begin{tabular}{|c|c|c|c|c|c|c|c|c|}
\hline \multirow[b]{2}{*}{ Study } & \multicolumn{4}{|c|}{ Methodological Characteristics } & \multicolumn{4}{|c|}{ Sample Characteristics } \\
\hline & Design & Activity & Measure & Frequency & $\underline{\text { Age }}$ & Gender & Country & $\underline{\mathbf{N}}$ \\
\hline Wang et al., 2003b & $\mathrm{D}$ & $\mathrm{PE}$ & $\overline{\text { CNAAQ-2 }}$ & 1 & $\mathrm{M}$ & $\mathrm{M}$ & Singapore & $3 \overline{4} 5$ \\
\hline Wang et al., 2004 & $\mathrm{D}$ & $\mathrm{S}$ & CNAAQ-2 & 1 & M & M & Singapore & 431 \\
\hline Wang et al. $2006 a$ & $\mathrm{D}$ & PA & CNAAQ-2 & 1 & $\mathrm{E}$ & $\mathrm{E}$ & Singapore & 1128 \\
\hline Wang et al., 2006b & $\mathrm{D}$ & $\mathrm{PE}$ & CNAAQ-2 & 1 & 0 & 0 & Singapore & 217 \\
\hline Wang \& Lui, 2007 & $\mathrm{D}$ & $\mathrm{PE}$ & CNAAQ-2 & 1 & M & $\mathrm{M}$ & Singapore & 343 \\
\hline Wang et al., 2009 & $\mathrm{D}$ & $\mathrm{S}$ & CNAAQ-2 & 1 & 0 & 0 & US & 309 \\
\hline Warburton \& Spray, 2008 & $\mathrm{~L}$ & $\mathrm{PE}$ & CNAAQ-2 & 2 & M & M & UK & 140 \\
\hline Warburton \& Spray, 2009 & $\mathrm{~L}$ & $\mathrm{PE}$ & CNAAQ-2 & 2 & M & $\mathrm{M}$ & UK & 511 \\
\hline Warburton \& Spray, 2013 & $\mathrm{~L}$ & PE & CNAAQ-2 & 2 & $\mathrm{M}$ & $\mathrm{M}$ & UK & 430 \\
\hline
\end{tabular}

Note. Design = Research Design: $\mathrm{D}=$ Descriptive, $\mathrm{E}=$ Experimental. Activity, $\mathrm{L}=$ Longitudinal. Activity Type: PA $=$ Physical Activity, $\mathrm{PE}=$ Physical Education, $\mathrm{S}=$ Sport. Age = Participant Age: $\mathrm{E}=5$ to 11 years, $\mathrm{M}=12$ to 14 years, $\mathrm{H}=15$ to 18 years, and $\mathrm{O}=$ Older than 18 years. 
Table 3. Outcome analyses for studies measuring implicit beliefs in activity contexts

\begin{tabular}{|c|c|c|c|c|c|c|c|c|c|c|}
\hline \multirow[b]{2}{*}{ Outcome } & \multicolumn{5}{|c|}{ Effect Size Statistics $^{1}$} & \multirow{2}{*}{$\frac{\text { Null Test }}{Z}$} & \multicolumn{3}{|c|}{ Heterogeneity Statistics } & \multirow{2}{*}{$\begin{array}{c}\text { Publication Bias } \\
\text { Fail Safe } \boldsymbol{N}\end{array}$} \\
\hline & $\boldsymbol{k}$ & $r_{-}$ & $S E$ & $s^{2}$ & $95 \% C I$ & & $Q$ & $\tau^{2}$ & $I^{2}$ & \\
\hline \multicolumn{11}{|l|}{ Random Effects Model } \\
\hline Entity-Adaptive & 23 & -0.11 & 0.02 & 0.001 & {$[-0.141,-0.082]$} & -7.46 & 49.54* & 0.002 & 55.59 & 770 \\
\hline Task Orientation & 10 & 0.012 & 0.03 & 0.001 & {$[-0.043,0.067]$} & 0.43 & $36.53^{*}$ & 0.005 & 75.36 & 0 \\
\hline Mastery Climate & 3 & -0.06 & 0.03 & 0.001 & {$[-0.125,-0.003]$} & $-2.04 *$ & 3.14 & 0.001 & 36.28 & 3 \\
\hline Enjoyment & 5 & -0.06 & 0.08 & 0.006 & {$[-0.205,0.090]$} & -0.76 & $34.49 *$ & 0.024 & 88.04 & 0 \\
\hline Perceived Competence & 12 & -0.02 & 0.02 & 0.001 & {$[-0.061,0.023]$} & -0.88 & $26.30 *$ & 0.003 & 58.17 & 0 \\
\hline RAI & 7 & -0.32 & 0.01 & 0.001 & {$[-0.343,-0.289]$} & $-23.16^{*}$ & 2.81 & 0.001 & 0 & 817 \\
\hline Intrinsic Motivation & 6 & -0.12 & 0.06 & 0.003 & {$[-0.237,-0.006]$} & $-2.07^{*}$ & $29.00 *$ & 0.014 & 82.76 & 34 \\
\hline MaP Goals & 9 & -0.10 & 0.02 & 0.001 & {$[-0.126,-0.061]$} & -5.63 & 4.79 & 0.001 & 0 & 64 \\
\hline Entity-Maladaptive & 19 & 0.17 & 0.02 & 0.001 & {$[0.120,0.209]$} & $7.28 *$ & $71.62 *$ & $\mathbf{0 . 0 0 7}$ & 74.86 & 1022 \\
\hline Ego Orientation & 9 & 0.14 & 0.02 & 0.001 & {$[0.107,0.169]$} & 8.68* & 9.40 & 0.001 & 14.85 & 195 \\
\hline Performance Climate & 3 & 0.34 & 0.03 & 0.001 & {$[0.280,0.408]$} & $10.57 *$ & 3.41 & 0.001 & 41.33 & 151 \\
\hline MaV Goals & 8 & 0.03 & 0.03 & 0.001 & {$[-0.037,0.089]$} & 0.82 & $19.61 *$ & 0.005 & 64.31 & 0 \\
\hline PaP Goals & 9 & 0.18 & 0.04 & 0.001 & {$[0.112,0.249]$} & $5.18^{*}$ & $32.94 *$ & 0.008 & 75.71 & 272 \\
\hline PaV Goals & 9 & 0.19 & 0.05 & 0.002 & {$[0.112,0.249]$} & $4.16^{*}$ & $57.24 *$ & 0.016 & 86.02 & 299 \\
\hline \multicolumn{11}{|l|}{ Random Effects Model } \\
\hline Incremental-Adaptive & 28 & 0.37 & 0.05 & 0.003 & {$[0.267,0.466]$} & $7.21 *$ & 935.02* & 0.069 & 97.11 & 3564 \\
\hline Task Orientation & 14 & 0.39 & 0.03 & 0.001 & {$[0.366,0.433]$} & $15.58 *$ & $45.60 *$ & 0.004 & 71.49 & 3214 \\
\hline Mastery Climate & 3 & 0.40 & 0.10 & 0.010 & {$[0.203,0.603]$} & $3.95 *$ & $33.25^{*}$ & 0.029 & 93.99 & 180 \\
\hline Enjoyment & 6 & 0.41 & 0.05 & 0.002 & {$[0.320,0.496]$} & $9.08 *$ & $19.15^{*}$ & 0.008 & 73.89 & 497 \\
\hline Perceived Competence & 13 & 0.27 & 0.03 & 0.001 & {$[0.208,0.331]$} & $8.57^{*}$ & 76.23 & 0.010 & 84.26 & 1591 \\
\hline RAI & 7 & 0.37 & 0.04 & 0.002 & {$[0.288,0.454]$} & $8.78 *$ & $45.11^{*}$ & 0.010 & 86.70 & 995 \\
\hline Intrinsic Motivation & 6 & 0.40 & 0.05 & 0.002 & {$[0.307,0.485]$} & $8.75 *$ & $11.32 *$ & 0.007 & 64.67 & 314 \\
\hline MaP Goals & 9 & 0.41 & 0.04 & 0.001 & {$[0.341,0.486]$} & $11.18^{*}$ & $45.48 *$ & 0.011 & 80.12 & 1679 \\
\hline Incremental-Maladaptive & 24 & 0.04 & 0.02 & 0.001 & {$[-0.009,0.083]$} & 1.57 & $122.41 *$ & 0.010 & 81.21 & 58 \\
\hline Ego Orientation & 14 & 0.04 & 0.03 & 0.001 & {$[-0.007,0.091]$} & 1.68 & $46.75^{*}$ & 0.006 & 72.19 & 0 \\
\hline Performance Climate & 3 & -0.12 & 0.03 & 0.001 & {$[-0.169,-0.071]$} & $-4.77 *$ & 2.13 & 0.001 & 5.96 & 14 \\
\hline MaV Goals & 8 & 0.17 & 0.03 & 0.001 & {$[0.103,0.232]$} & $5.06 *$ & $20.87 *$ & 0.006 & 66.46 & 156 \\
\hline PaP Goals & 9 & 0.09 & 0.05 & 0.003 & {$[-0.011,0.191]$} & 1.47 & 73.38* & 0.013 & 89.10 & 0 \\
\hline PaV Goals & 9 & 0.02 & 0.06 & 0.003 & {$[-0.094,0.125]$} & 0.28 & $86.20 *$ & 0.025 & 90.72 & 0 \\
\hline
\end{tabular}

Note. ${ }^{*} \mathrm{p} \leq .05 .{ }^{\dagger}$ Fisher's $Z$ was used to calculate effect size statistics. $k=$ number of effect sizes. $r_{-}=$uncorrected effect size (Pearson's $r$ ). $S E=$ standard error. $S^{2}=$ variance used in combination with Fisher's $Z$ to calculate summary effects. 95\% $C$. $I$. = confidence intervals (lower limit, upper limit). $Z=$ test of null hypothesis. $Q=$ Total $Q$-value used to determine heterogeneity. $\tau^{2}=$ between study variance in random effects model. $I^{2}=$ total variance that could be explained by moderators. 
Table 4. Moderator analyses for incremental beliefs in activity contexts for adaptive outcomes

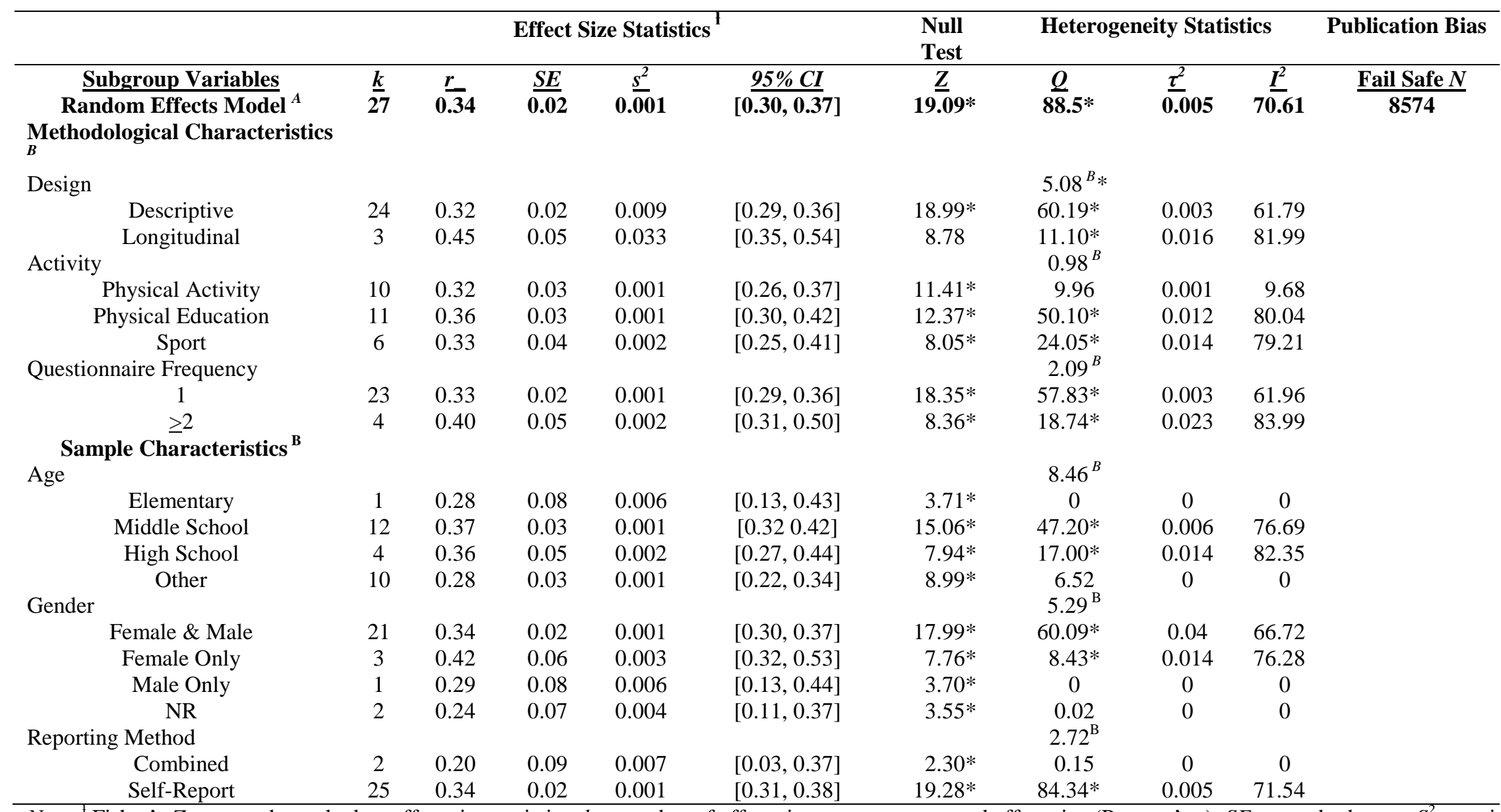

Note. ${ }^{t}$ Fisher's $Z$ was used to calculate effect size statistics. $k=$ number of effect sizes. $r$ = uncorrected effect size (Pearson's $r$ ). $S E=$ standard error. $S^{2}=$ variance. $95 \%$ CI. $=$ confidence intervals (lower limit, upper limit). $Z=$ test of null hypothesis. $\tau^{2}=$ between study variance in random effects model. $I^{2}=$ total variance unexplained by moderator. * indicates $\mathrm{p}<.05$. A $=$ Total $Q$-value used to determine heterogeneity. $\mathrm{B}=$ Between $Q$-value used to determine significance between subgroups $(\alpha<0.05)$. 
Table 5. Moderator analyses for incremental beliefs in activity contexts for maladaptive outcomes

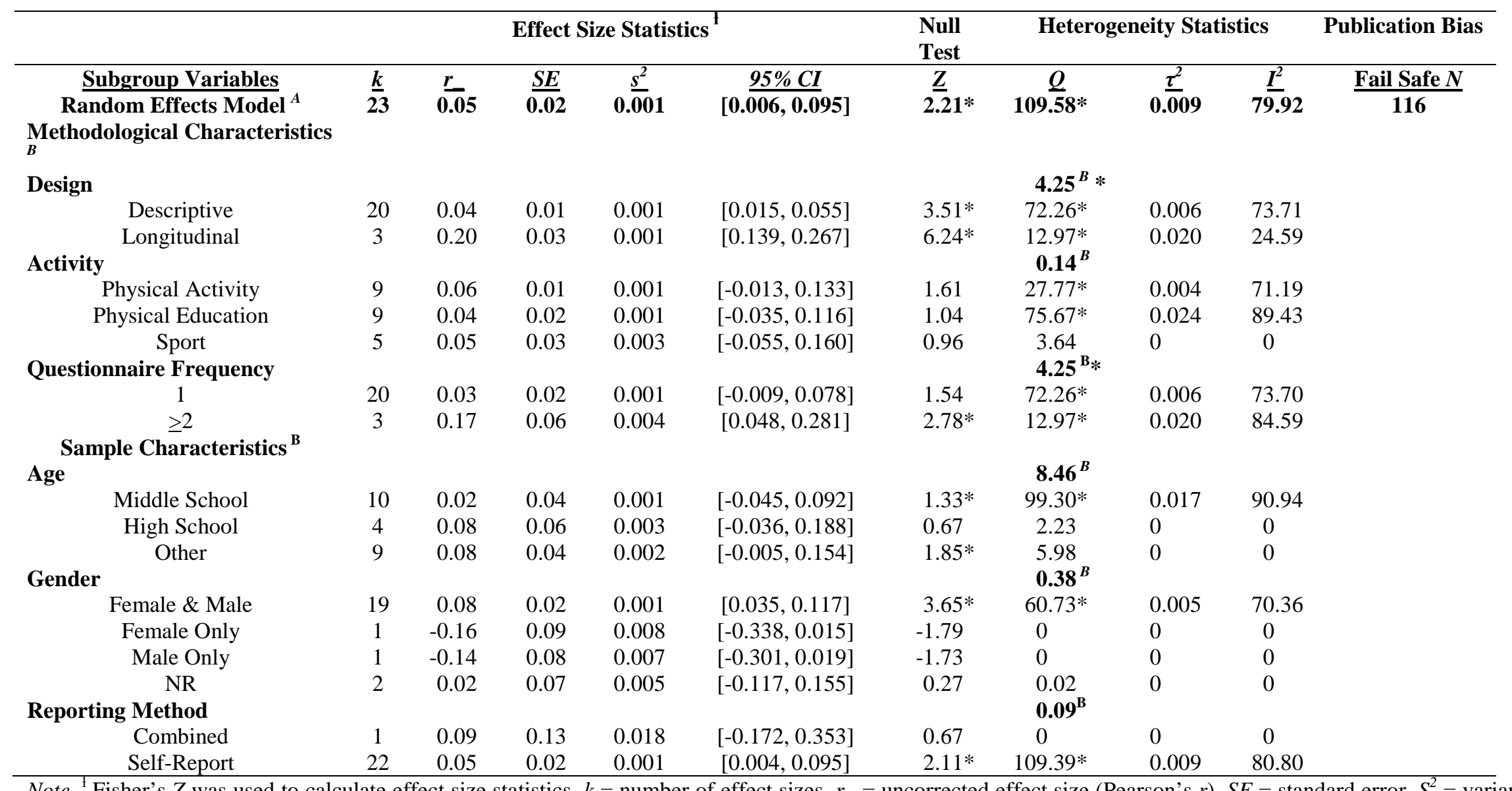

Note. ${ }^{\dagger}$ Fisher's $Z$ was used to calculate effect size statistics. $k=$ number of effect sizes. $r_{-}=$uncorrected effect size $($Pearson's $r) . S E=$ standard error. $S^{2}=$ variance. $95 \%$ CI $=$ confidence intervals (lower limit, upper limit). $Z=$ test of null hypothesis. $\tau^{2}=$ between study variance in random effects model. $I^{2}=$ total variance unexplained by moderator. * indicates $\mathrm{p}<.05$. A = Total $Q$-value used to determine heterogeneity. B = Between $Q$-value used to determine significance between subgroups $(\alpha<0.05)$ 
Table 6. Moderator analyses for entity beliefs in activity contexts for adaptive outcomes

\begin{tabular}{|c|c|c|c|c|c|c|c|c|c|c|}
\hline \multirow[b]{2}{*}{$\begin{array}{c}{ }_{\text {Rubgroup Variables }} \\
\text { Random Effects Model }^{A} \\
\text { Iethodological Characteristics }\end{array}$} & \multicolumn{5}{|c|}{ Effect Size Statistics ${ }^{\top}$} & \multirow{2}{*}{$\begin{array}{c}\begin{array}{c}\text { Null } \\
\text { Test }\end{array} \\
\underline{Z} \\
-7.70 *\end{array}$} & \multicolumn{3}{|c|}{ Heterogeneity Statistics } & \multirow{2}{*}{$\begin{array}{c}\text { Publication Bias } \\
\frac{\text { Fail Safe } N}{815}\end{array}$} \\
\hline & $\frac{k}{23}$ & $-\frac{r}{-12}$ & $\frac{S E}{0.02}$ & 0.001 & $\frac{95 \% C I}{[-0.14,-0.09]}$ & & $\frac{Q}{49.46 *}$ & 0.002 & $\frac{I^{2}}{55.52}$ & \\
\hline Design & & & & & & & $11.90^{B} *$ & & & \\
\hline Descriptive & 19 & -0.13 & 0.01 & 0.001 & {$[-0.15,-0.10]$} & $-9.38 *$ & $32.64 *$ & 0.001 & 44.86 & \\
\hline Experimental & 1 & 0.12 & 0.07 & 0.005 & {$[-0.02,0.27]$} & 1.66 & 0 & 0 & 0 & \\
\hline Activity & 3 & -0.08 & 0.04 & 0.002 & {$[-0.16,-0.01]$} & $-2.03 *$ & $\begin{array}{l}0.33 \\
\mathbf{1 . 4 1}^{B}\end{array}$ & 0.001 & 0 & \\
\hline Physical Activity & 10 & -0.13 & 0.02 & 0.001 & {$[-0.17,-0.09]$} & $-6.03 *$ & 13.99 & 0.001 & 35.67 & \\
\hline Physical Education & 10 & 0.09 & 0.02 & 0.001 & {$[-0.14,-0.05]$} & $-3.83 *$ & $28.70^{*}$ & 0.007 & 68.65 & \\
\hline Sport & 3 & -0.14 & 0.05 & 0.002 & {$[-0.24,-0.05]$} & $-2.97 *$ & 2.84 & 0.002 & 29.81 & \\
\hline Questionnaire Frequency & & & & & & & $0.21^{B}$ & & & \\
\hline 1 & 19 & -0.12 & 0.02 & 0.001 & {$[-0.15,-0.07]$} & $-7.26 *$ & $47.45^{*}$ & 0.003 & 62.07 & \\
\hline$\stackrel{\geq 2}{\text { Sample Characteristics }^{\text {B }}}$ & 4 & -0.10 & 0.04 & 0.002 & {$[-0.18,-0.01]$} & $-2.30^{*}$ & 1.16 & 0 & 0 & \\
\hline Age & & & & & & & $3.07^{B}$ & & & \\
\hline Elementary & 1 & -0.16 & 0.16 & 0.004 & {$[-0.28,-0.04]$} & $-2.68 *$ & 0 & 0 & 0 & \\
\hline Middle School & 11 & -0.11 & 0.02 & 0.001 & {$[-0.15,-0.07]$} & $-5.24 *$ & $35.86 *$ & 0.005 & 72.11 & \\
\hline High School & 2 & -0.04 & 0.05 & 0.003 & {$[-0.14,0.06]$} & -0.86 & 0.57 & 0 & 0 & \\
\hline Gender & 9 & -0.13 & 0.03 & 0.001 & {$[-0.19,-0.08]$} & $-4.97 *$ & $\begin{array}{l}5.38 \\
\mathbf{6 . 7 1}^{B_{*}}\end{array}$ & 0 & 0 & \\
\hline Female \& Male & 19 & -0.11 & 0.02 & 0.001 & {$[-0.14,-0.08]$} & $-7.08 *$ & $36.18 *$ & 0.002 & 50.26 & \\
\hline Female Only & 3 & -0.22 & 0.05 & 0.002 & {$[-0.31,-0.13]$} & $-4.91 *$ & 2.69 & 0.001 & 25.69 & \\
\hline Male Only & 1 & -0.06 & 0.06 & 0.003 & {$[-0.17,-0.05]$} & -1.04 & 0 & 0 & 0 & \\
\hline Reporting Method & & & & & & & $1.59^{B}$ & & & \\
\hline Combined & 2 & -0.22 & 0.08 & 0.006 & {$[-0.37,-0.07]$} & $-2.85 *$ & 0.26 & 0 & 0 & \\
\hline Self-Report & 21 & -0.11 & 0.02 & 0.001 & {$[-0.14,-0.08]$} & $-7.35 *$ & $47.07 *$ & 0.002 & 57.52 & \\
\hline
\end{tabular}

Note. ${ }^{t}$ Fisher's $Z$ was used to calculate effect size statistics. $k=$ number of effect sizes. $r=$ uncorrected effect size (Pearson's $r$ ). $S E=$ standard error. $S^{2}=$ variance. $95 \%$ C. $I$. $=$ confidence intervals (lower limit, upper limit). $Z=$ test of null hypothesis. $\tau^{2}=$ between study variance in random effects model. $I^{2}=$ total variance unexplained by moderator. * indicates $\mathrm{p}<.05$. A $=$ Total $Q$-value used to determine heterogeneity. $\mathrm{B}=$ Between $Q$-value used to determine significance between subgroups $(\alpha<0.05)$. 
Table 7. Moderator analyses for entity beliefs in activity contexts for maladaptive outcomes

\begin{tabular}{|c|c|c|c|c|c|c|c|c|c|c|}
\hline & \multicolumn{5}{|c|}{ Effect Size Statistics ${ }^{\dagger}$} & $\begin{array}{c}\begin{array}{c}\text { Null } \\
\text { Test }\end{array} \\
\underline{Z}\end{array}$ & \multicolumn{3}{|c|}{ Heterogeneity Statistics } & $\begin{array}{r}\text { Publication Bias } \\
\underline{\text { Fail Safe } N} \\
\end{array}$ \\
\hline$\underset{\text { Methodological Characteristics }_{\text {Random Effects Model }^{A}}}{\text { Subgroup Variables }}$ & $\frac{k}{18}$ & $\frac{r}{0.15}$ & $\frac{S E}{0.02}$ & $\frac{s^{2}}{0.001}$ & $\frac{95 \% C I}{[0.11,0.19]}$ & 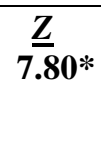 & $\underset{50.12}{Q}$ & 0.004 & $\frac{I^{2}}{66.09}$ & $\frac{\text { Fail Safe } N}{829}$ \\
\hline Design & & & & & & & $3.81^{B}$ & & & \\
\hline Descriptive & 15 & 0.17 & 0.02 & 0.001 & {$[0.13,0.21]$} & $8.23 *$ & $42.11^{*}$ & 0.004 & 66.75 & \\
\hline $\begin{array}{l}\text { Longitudinal } \\
\text { Activity }\end{array}$ & 3 & 0.07 & 0.05 & 0.002 & {$[-0.03,0.16]$} & $1.31 *$ & $\begin{array}{c}1.66 \\
\mathbf{0 . 1 6}\end{array}$ & 0 & 0 & \\
\hline Physical Activity & 8 & 0.16 & 0.03 & 0.001 & {$[0.10,0.22]$} & $5.29 *$ & 10.87 & 0.001 & 35.61 & \\
\hline Physical Education & 7 & 0.14 & 0.03 & 0.001 & {$[0.08,0.21]$} & $4.20 *$ & $27.87 *$ & 0.010 & 78.47 & \\
\hline $\begin{array}{c}\text { Sport } \\
\text { Questionnaire Frequency }\end{array}$ & 3 & 0.16 & 0.06 & 0.003 & {$[0.05,0.27]$} & $2.84^{*}$ & $\begin{array}{r}10.86^{*} \\
\mathbf{0 . 2 4}\end{array}$ & 0.020 & 81.58 & \\
\hline 1 & 15 & 0.17 & 0.02 & 0.001 & {$[0.13,0.21]$} & $8.23 *$ & $42.11^{*}$ & 0.004 & 66.75 & \\
\hline Sample Characteristics $^{\text {B }}$ & 3 & 0.07 & 0.05 & 0.002 & {$[-0.03,0.16]$} & 1.31 & 1.66 & 0 & 0 & \\
\hline Age & & & & & & & $3.08^{B}$ & & & \\
\hline Middle School & 9 & 0.13 & 0.03 & 0.001 & {$[0.08,0.18]$} & $4.97 *$ & $29.78 *$ & 0.004 & 73.13 & \\
\hline High School & 2 & 0.24 & 0.06 & 0.003 & {$[0.13,0.35]$} & $4.19 *$ & 3.31 & 0.006 & 69.78 & \\
\hline Gender & 7 & 0.16 & 0.03 & 0.001 & {$[0.09,0.23]$} & $4.67 *$ & $\begin{array}{l}10.09 \\
\mathbf{8 . 6 4}\end{array}$ & 0.003 & 40.54 & \\
\hline Female \& Male & 16 & 0.15 & 0.02 & 0.001 & {$[0.11,0.18]$} & $8.47 *$ & $30.07 *$ & 0.002 & 50.12 & \\
\hline Female Only & 1 & 0.05 & 0.07 & 0.005 & {$[-0.09,0.19]$} & 0.70 & 0 & 0 & 0 & \\
\hline Male Only & 1 & 0.31 & 0.06 & 0.004 & {$[0.19,0.42]$} & $5.09 *$ & 0 & 0 & 0 & \\
\hline Reporting Method & & & & & & & $0.42^{B}$ & & & \\
\hline Combined & 1 & 0.08 & 0.12 & 0.013 & {$[-0.14,0.31]$} & 0.70 & 0 & 0 & 0 & \\
\hline Self-Report & 17 & 0.16 & 0.02 & 0.001 & {$[0.12,0.19]$} & $7.73 *$ & 49.52* & 0.004 & 67.69 & \\
\hline
\end{tabular}

Note. ${ }^{1}$ Fisher's $Z$ was used to calculate effect size statistics. $k=$ number of effect sizes. $r_{-}=$uncorrected effect size (Pearson's $r$ ). $S E=$ standard error. $S^{2}=$ variance. $95 \%$ CI. $=$ confidence intervals (lower limit, upper limit). $Z=$ test of null hypothesis. $\tau^{2}=$ between study variance in random effects model. $I^{2}=$ total variance unexplained by moderator. * indicates $\mathrm{p}<.05$. A = Total $Q$-value used to determine heterogeneity. $\mathrm{B}=$ Between $Q$-value used to determine significance between subgroups $(\alpha<0.05)$. 


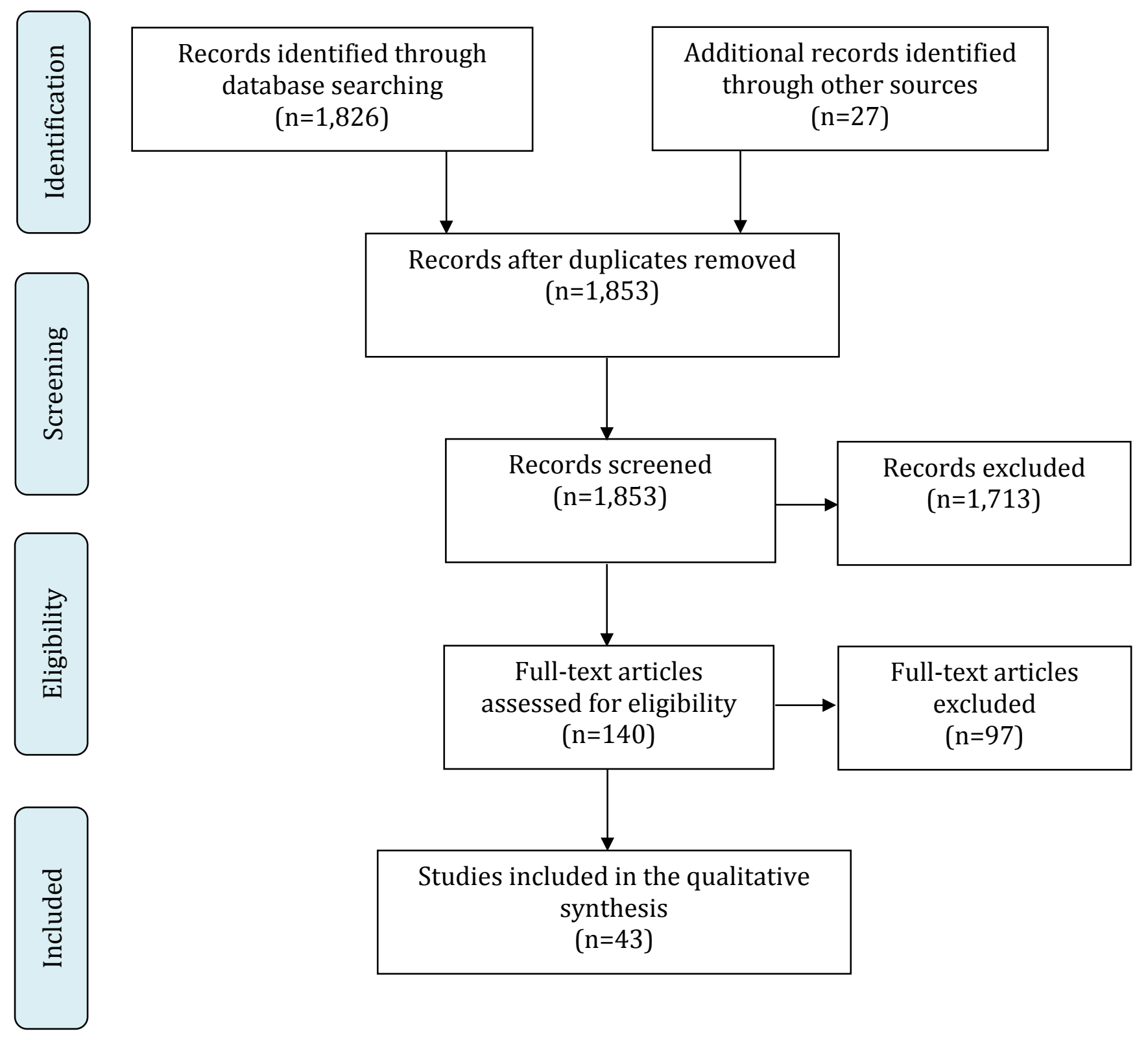

Figure 1. PRISMA Flow diagram of Literature search. 